\title{
Installation of a reinforced-concrete invert in the Gillingham (Dorset) Tunnel on the Southern Region of British Railways
}

by

\author{
P. W. Tanner, A.M.I.C.E. \\ and \\ R. A. H. Burton, B.E., A.M.I.C.E., A.M.N.Z.I.E.
}

Mr A. H. Cantrell (Chief Civil Engineer, British Railways, Southern Region) said that the Paper drew attention to the difficulty which existed in the maintenance of tunnels. There were quite a number of tunnels which in the past had given trouble or were still giving trouble, and he had often heard people say that this was due to bad construction in the first place. He had a great admiration for the early engineers who built these tunnels, for they had had no previous experience on which to go and they had done their best. Many tunnels of more than 100 years old were still excellent. If we were to build tunnels nowadays which gave trouble in 100 years, we should probably be to blame, because there was far more information available today about soil mechanies and construction than in those days.

66. Nevertheless, maintenance difficulties arose with some of these old tunnels. There had been a paper about Bo Peep Tunnel, where the problem had had to be tackled very quickly and the tunnel temporarily closed to traffic. It had been lined with cast iron. There had also been Ore Tunnel, which had been tackled in a fairly similar way to that described by the Authors. Gillingham Tunnel had been difficult for many years. In the early part of the century movement had started, but the engineer in charge, in order to give clearance to the coaches, had lowered the track between $1 \mathrm{ft}$ and $18 \mathrm{in}$. This had been a dreadful thing to do, because it had immediately reduced the support on the side walls and the weight on the invert.

67. Getting still more trouble, the next thing done was to put timber struts across the worst places. This had given a little temporary improvement but no permanent improvement. About fifteen years ago a certain amount of concrete invert had been put in the worst places to try to hold the situation. One of the most important decisions which one had to make from a maintenance point of view was whether to close the tunnel and make a good engineering job of it or to do the best possible to it by keeping the traffic running. Fifteen years ago they had tried to do their best while keeping the traffic running and they had put a concrete invert in the worst places, but, unfortunately, it had not been very successful. Consequently, when trouble had occurred in the other part of the tunnel adjacent to the invert, it was decided that there must be an investigation.

68. The Paper showed excellently how a scientific investigation and a first-class thinking out of how the job could be done had gone hand in hand most successfully. They had to take the plunge in so far as they wanted one track closed at a time. Fortunately, the traffic in Dorset was not as heavy as near London, and the operating department had been only too willing to help during winter traffic by closing one road at a time and giving the facilities described in the Paper. It had therefore been

* Proc. Instn civ. Engrs, vol. 24, January 1963, pp. 61-82. 
possible to get on with the job. It had been very ticklish working, but thanks to the efforts of those on the site, it had gone very well indeed.

69. Reference was made in the Paper to leaving a clearance for overhead electrification wires. This might puzzle some present, but the job had to be started when the Southern Region were thinking of extending electrification towards the West of England. National planning was that overhead electrification, rather than third rail, should be the future method. Faced with this situation, he had decided that he must allow for overhead conductors, and this was the reason that so much headroom had been adopted. This had made the scheme more expensive, but if subsequent overhead electrification had been made impossible because of a tunnel recently reconstructed, there would have been some serious criticism.

70. He would not say too much about the work. The slides showed the dreadful conditions before the work was done, but were nevertheless an accurate picture. One point which had not been brought out was that the old brick invert which failed had come up so that it was in contact with the bottom of the sleepers, some of which were breaking their backs. It had been decided to cut away the top of the brickwork, but this had been only a temporary measure, and it was essential to go in for a thorough job. This had been very successful. He was sorry to say that it had been handed over to the Western Region, but was sure that it would not give them any trouble.

Mr F. A. Sharman (Senior Engineer, Sir William Halcrow \& Partners) said that he would venture to be a little critical of some of the analytical work in the Paper, but he must say first that it was a most admirable record of the successful solution of an intricate engineering problem. From the practical point of view, it appeared that correct decisions had been made at all stages and he had no doubt that they were guided by a true understanding of the practical requirements and by an overall grasp of the whole situation. However, in their enthusiasm to justify themselves mathematically, the Authors had been led into some doubtful and possibly misleading statements.

72. The term 'swelling pressures' was used in $\$ \$ 13$ and 16 in a rather loose way. The 1.25 tons/sq. $\mathrm{ft}$ stated as having been measured on twelve undertrack samples, presumably in oedometer tests, might indeed indicate some residual thrust that might be exerted on a rigid boundary under particular pore pressure conditions, but it hardly seemed relevant to the reaction between track ballast and heaving clay when footings were punched in to an extent that must produce substantial remoulding. The conclusion that further softening must be expected was certainly true unless the moisture content could be kept low enough to maintain a large negative pore pressure, but the citing of an arbitrary and artificial figure did not seem to help one's judgment of probable behaviour in any way.

73. In $\S 16$ it was hard to follow why swelling pressures equal to full overburden load were supposed to have been present during the early life of the tunnel and to have built up again after plastic stress redistribution following failure of the invert. Surely the stress history was more likely to have been a gradual increase to a maximum value just before failure, followed by a release of pressure when the lining began to penetrate the invert.

74. The thrust line computation illustrated in Fig. 7 did not appear to represent any possible state of affairs. A somewhat similar approach was used for the Woodhead Tunnel lining by Scott and Campbell, ${ }^{4}$ but in that case the argument had been that if the thrust line was going to remain in the middle third of the concrete lining of a rock tunnel, the rock in contact with the lining would have had to mobilize certain reactions on each segment considered in the analysis. Since those reactions proved to be well within the capability of the rock without involving corresponding strains that would have caused excessive deflexions of the concrete in contact with it, it was 
deduced that the lining thickness was adequate. In this case, however, the Authors had allowed the thrust line to pass from the lining into a material of entirely different elastic properties and the only valid deduction from the funicular polygon could have been reached with much less labour by considering the total horizontal and vertical forces to be resisted at the crown and footing. It was suggested that a more realistic approach to stress distribution would be found by the methods given in a paper by H. D. Morgan. ${ }^{8}$ The assumption that some stresses could usefully be computed to $C=0, \phi=0$ was hard to justify, since in such circumstances the tunnel would be nothing but a sausage-shaped bubble in a heavy liquid and would be likely to rise to the surface with disconcerting results to the traffic.

75. The factors of safety computed in $\S 18$ were clearly unrealistic and a more productive approach might have been to assume that the factor was unity when the arch was known to be on the verge of movement, and to deduce the average properties of the clay by working backwards.

76. It would be interesting if the basis of using a factor of $5.5 \times$ cohesion could be explained. The footings were quite deep, and failure could only take place on one side, so that one might expect that the factor would be higher, perhaps approaching 8 or 8.5 . In $\S 20(e)$ perhaps the Authors would reveal whether the inward thrust used to calculate the required strut strength had been taken from the Fig. 7 calculation. If so, there appeared a very high built-in factor of safety. Again, in $\$ 20(f)$ it would seem excessive to use a factor of safety of 2 against stresses caused by full overburden pressure which in practice scarcely could be exceeded. The probable distribution of load would also reduce the bearing pressure on the footings and it might have been more economical to deduce from the observed behaviour of the footings what minimum properties of the clay could be assumed. No doubt the possibility of building the invert in a true arch had been considered, but it was easy to accept that in the circumstances it was more practicable to construct the system described without attempting to refine the design any further.

77. However, the success of the enterprise had justified all the decisions taken.

Mr A. H. Toms (Research Assistant to Chief Civil Engineer, British Railways, Southern Region) said that Mr Cantrell had mentioned examples of previous tunnels, one of which had nearly overwhelmed them-Bo Peep Tunnel. If anybody thought that they relied entirely on soil mechanics tests as a basis for design, he was mistaken. They merely used these tests as a means to improve their knowledge of the conditions in these tunnels. But at all times the decisions which had been taken had been engineering judgments, guided by soil mechanics tests and the evidence which $\mathrm{Mr}$ Burton and the team had produced under most arduous conditions.

79. Figs 6 and 3 were the crux of the situation. What was shown were the changes in cross-sections in recent or ancient history and the marked difference in the characteristics of the clay in the two halves of the tunnel. These readily explained what the Authors had been trying to find out. In Hastings Tunnel the footings had turned their toes up in the air and had split off the side walls over a short length. These had been dealt with in between the Bo Peep and Ore Tunnel jobs.

80. Those who had read the history of Penge Tunnel, which went through London clay, knew that it was not until the resident engineer had said that the tunnel would keep collapsing until it was made circular in section that continuing deformation had been prevented. It had been made into almost a circle over the troublesome length, and sleeper ends had to be cut short because of that.

81. Working back from that experience, it would be found that whatever refinement one did in the calculation-and they openly admitted that the things which $\mathrm{Mr}$ Burton had quoted were only rough shots to get some idea of the forces, the ultimate answer was governed by this type of experience. It was essential to play safe. It was very costly to get into a tunnel to do a job, and it did not pay to skimp 
it once one was in the tunnel. Bo Peep had shocked those concerned because the development in the end had been very swift and had almost overwhelmed them.

82. Everybody appreciated that there was a large volume of soil around the tunnel and that one could only sample a minute fraction of it. It was necessary to try to site the tests strategically and to get the best possible out of a small amount of information.

83. It was important to ascertain the nature of the movements, and to do this, every bit of history was necessary. But, as Mr Burton and others had found, one was often up against a brick wall. Gillingham had been no exception. Even the geologists had not been able to explain everything around the tunnel, and the full answer was still not known.

84. Comment had been made on the effect of variations of pressure assumptions and doubts had been expressed about swelling pressures. Swelling tests on block samples of Weald clay from Crawley had shown swelling pressures greater than the overburden. The assumption made in this case--similar to results arrived at by Tattersall, Wakeling, and Ward ${ }^{3}$-had been that the ratio of lateral and vertical pressures to the overburden at any depth was about 0.75 , He thought that the assumptions made in this case had been legitimate.

85. Finally, he drew attention to the extreme importance of the regular checking of tunnel profiles.

86. Conventional methods were very time-consuming, and inquiries had been made into optical scanning methods. There were snags in getting accuracy. The scanning was done by a narrow light beam rotating about the tunnel axis, the result being photographed from the moving carriage. Discussions had been held with experts on the use of radar for the same thing, but in the end they had come back to sonic methods. The specialists who had been consulted had evidently encountered difficulties and had not produced an answer.

Dr W. H. Ward (Head, Soil Mechanics Division, Building Research Station) said it was useful to have a case record of an old tunnel which had slowly failed. It was easy enough to criticise its design, but it should be remembered that at the time of construction the clays were much stronger than the Authors had found during the repair work and the original builders did not know enough about the properties of over-consolidated clays to realize that it was essential to provide a lining which was a complete ring.

88. Many early tunnels had been built without inverts, and this arrangement was satisfactory provided the footings were secured into a thick bed of strong stable rock such as sandstone or limestone. Evidently the builders met difficulties in construction that led them to insert short lengths of invert. Those invert sections proved to be unsatisfactory, and clearly the whole tunnel should have been constructed with an invert, preferably of circular form.

89. On account of the dip and the variety of the strata there might be some difficulties in interpreting the soil tests, but he felt sure that the closure and upheaval of the invert were associated with stiff clays that had swelled and softened slowly in the vicinity of the invert. It would be of value in this connexion to plot out Fig. 3 of the Paper, which showed the tunnel movements, against the types of strata at the invert; unfortunately, Figs 3 and 4 were not drawn to the same scale, their directions were reversed and the soil tests were not closely identified with the stratigraphy.

90. There had been adverse criticism of the stability calculations on the lining presented in the Paper. There was only a limited amount of information available to the Authors and they had been faced with making a number of assumptions, in order to make any calculation. Those which the Authors had used did not appear to be completely unreasonable for the purpose of calculating approximately the present loads on the footing.

91. The lining was slowly yielding on account of a footing failure; consequently 
the magnitude and direction of the forces acting in the lining varied with time. The more the lining yielded, the less load it could mobilize and the more the ground was called upon to support itself. Consequently the so-called line-of-thrust from the upper part of the lining might well emerge outside the ring. This meant that the lower part of the lining was not a very effective support for its upper part, which was the case. The horizontal fractures in the side wall shown in Fig. 14 of the Paper suggested that the thrust was at least near the outside of the wall and that the ground alongside carried considerable vertical load.

Mr E. J. C. Reed (retired) said that the Paper was a good example of a thorough investigation, careful planning and careful carrying out of the work. If work like this could be carried out without having to carry traffic over the work, it could be done in about one-third of the time, making a much better job and with less likelihood of injury to personnel.

93. At the Bo Peep Tunnel they had not been so fortunate. In that case the side walls had been going down in one length at $\frac{1}{4}$ in. a day, and the invert had to be done in one piece from side to side underneath each wall. It would not have been satisfactory to go under one wall and to do the other afterwards.

94. He was not so sure in this case that the line of thrust passed outside the tunnel lining. He was inclined to think that there was sufficient passive resistance in the clay to force the line of thrust back into the lining.

95. He was not a lover of old rails when they were used as reinforcement. They were cheap and readily available, but he did not like them nor the joint very much. At the same time, if any welding had been done on the fish plate to fix them to the head and foot of the rail, the welder having to do overhead welding would have had great difficulty in getting out, unless the rails were turned upright.

96. He had imagined, at first, that the 10-7 mixers would not be big enough for the work, but, on second thoughts, they had been quite adequate and there had been no need for anything larger. They had been kept at full blast during the time of concreting, and he understood that there had been no delay in delivery to the site.

97. The invert slab, between 0 and 18 chains where the full depth of invert was not constructed continuously, was keyed into the full section of invert, and it was a good plan to do this; otherwise, with any uplift on that slab, the face bricks of the side walls at the junction with the slab might well be pushed off.

Mr D. G. Williams (District Engineer, British Railways, Exeter Central) said that it was evident that owing to the limitation imposed on the length of the Paper, the Authors had been able only briefly to mention the early history of the defects in the tunnel. He hoped that it would be of interest if he amplified that part of the subject.

99. The Paper read to the Institution in 1863 and one other source provided about the only early records of the tunnel. They gave the information that the excavation was for the most part in a silty blue clay with layers of sand and sandstone rock, as shown in Fig. 4 in the Paper under discussion. On that longitudinal section was shown a 'Top Heading'. That had apparently been driven above the level of the tunnel for a distance of about 200 yds to collect a great quantity of water which had hampered the construction work. In fact, the water, which was very clean and pure, still flowed constantly and provided a piped supply to a locomotive depot about 4 miles away.

100. It was known, therefore, that conditions in the western half of the tunnel had always been wet. It was also known that when the structure was about sixty-five years old, it had become necessary to lower the tracks in that part because of the extent to which the formation had risen. Probably the movement had proceeded slowly, from the time when the line was opened, and had not occurred suddenly.

101. In 1927, with the object of improving the track conditions, numerous concrete slabs had been laid under the 'up' and 'down' lines in the western half of the 
tunnel and a drain had been laid along the 'six-foot' way. As the drain had interrupted the continuity of the slabs, they had not functioned as struts or as an invert between the side walls. They might have been effective locally, however, as a blanket.

102. When these concrete mats had been laid about thirty-five years ago, there had been 6 in. depth of ballast below the underside of the sleepers. After twenty years, however, the concrete in certain places under the 'up' line had risen so much that the ganger had had to cut away the underside of some sleepers to keep the track at the required level. Parts of the drain had been relaid several times, but it had again humped and had been impeding the flow of water, in spite of the longitudinal gradient of 1 in 100 throughout the tunnel.

103. In 1948 a concrete invert, with the underside $4 \mathrm{ft}$ below rail level, had been constructed for a length of $68 \mathrm{ft}$ between 20 chains and 21 chains approximately, measured from the eastern end of the tunnel. During that work, it had been necessary to cut away parts of the concrete mats that had been laid in 1927 and also parts of the deeper brick invert built in 1859. It could be clearly seen that this invert had broken its back.

104. It seemed probable that the noticeable variations in the tunnel profile had not existed when the structure was built and so, in order to establish whether inward movement of the side walls was continuing, measuring pins and bench marks had been fixed. Thereafter dimensions and levels had been checked periodically.

105. The Authors had described, admirably, the conditions that had been reached by 1957 and also the preparation of designs for the two types of invert that would act as a strut between the side walls and would resist bending due to the upward pressure of the subsoil.

106. The $68 \mathrm{ft}$ length of invert, laid in 1948 to a depth of $4 \mathrm{ft}$ below rail level, had involved eight periods of twenty hours each at week-ends during which the lines had been blocked. It had been obvious, therefore, that for the work commencing in 1958 , facilities must be provided for the operations to continue night and day. It would be seen that the scheme allowed the normal train service to continue uninterruptedly and with almost negligible delays.

107. The arrangement of the temporary crossovers leading to the single line had enabled the occupied line to be changed from 'up' to 'down' and vice versa very quickly and this had been a highly commendable feature of the scheme. It had contributed considerably to the ease with which the sections of the new invert could be formed in accordance with a sequence-shown in Fig. 10 of the Paper-so as to maintain strutting between the tunnel walls throughout the operations.

108. It was to be noted that narrow gauge tramway had not been required. Power-driven platelayers' trolleys with trailers had been available in the district and, with some ingenious adaptation, they had been very successful as a means of conveying spoil and concrete by running on whichever one of the tracks was under possession. They could readily be transferred to the other line and they had worked in conjunction with the duplicated facilities for tipping spoil and mixing concrete.

109. By the time the whole invert had been finished, there had inevitably been some disturbance of track sleepers and fastenings, but, fortunately, track renewal would have been required even under normal circumstances. Accordingly, there were newly-laid and reballasted tracks which showed no tendency to become displaced. Moreover, continuing check measurements in the tunnel had shown that there had been no measureable movement.

Mr R. A. Shewring (Senior Engineer, Messrs A. J. and J. D. Harris, Consulting Engineers) said he found that section of the Paper dealing with the construction particularly interesting, as he had been Resident Engineer for C. H. Dobbie and Partners, who had designed and supervised similar work on behalf of the Midland Region of British Railways.

111. It was surprising to read that the work was carried out by so few men over 
such a long period. Was this the economic method of working in the circumstances where traffic had to be maintained? Would the Authors say how long each $120 \mathrm{ft}$ bay had taken to complete, and also, where in $\S 31$ it was stated that work ceased for about three months each year, would they say whether the plant was used for operations elsewhere during this time? Would the Authors say in which direction work proceeded?

112. Was there any particular reason for using an all-in aggregate as mentioned in $\$ 54$ and would the Authors give the design strength of the invert concrete? Finally, could the Authors comment on the state and strength of the brickwork broken out from the side wall footings, and would they say whether this was particularly hard to break out?

113. Mr Shewring showed several slides, illustrating the construction of a reinforced concrete invert to one of three existing tunnels which bypassed the main junction at Crewe Station. These tunnels, built in open cut in 1892, consisted of vertical brick walls on concrete strip footings with plated roof girders at $5 \mathrm{ft}$ centres and brick jack arches between; no records of the original construction remained. Replacement of the roof by any shallower form of construction to give the increased overhead clearance required for electrification would have dislocated the very large volume of traffic which passed through the main junction above and it was therefore decided to lower the tracks by the $1 \mathrm{ft} 6$ in. required. Preliminary boreholes had revealed very soft ground underlying the wall footings of the double track Manchester tunnel and to contain this soft ground, a system of steel sheet piling, driven close to the side of the footings, with temporary strutting between was devised to prevent any possible inward movement of the footings and walls after the $4 \mathrm{ft}$ depth of excavation for the new invert had been removed.

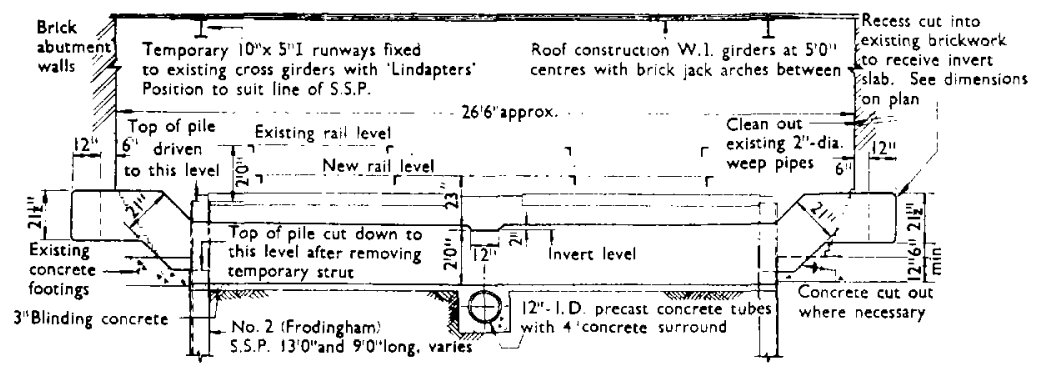

Fig. 23: TYPICAL SECTION THROUGH TUNNEL

114. Some of the slides showed the difficulties of driving the $28000 \mathrm{sq}$. ft of No. 2 A.F. sheet piling using cradles in the restricted headroom. In some areas the driving proved much harder than anticipated entailing the use of No. 6 McKiernan-Terry hammers and these piles were not driven to their full depth. The temporary installation of $10 \mathrm{in.} \times 5$ in. R.S.J. overhead runway beams with geared trolleys had been invaluable in handling the piles into the tunnel, these having been formed into panels of ten piles outside each portal and then trolleyed in. (For a typical section through tunnel, see Fig. 23.) Also installed at roof level had been a 6. in.-dia. compressed air main with numerous outlet manifolds to which the piling hammers were connected and also the jack hammers for breaking out the brickwork at footing level.

115. Piling had commenced at the centre of the tunnel working simultaneously outwards to the portals, excavation and temporary strutting following in sequence. A total of $6200 \mathrm{cu}$. yd of excavated material had been removed by two J.C.B. excavators, loaded into trains of four to five jubilee wagons hauled to the portals by 
light 'Simplex' locos, each excavator being served by two such trains to maintain continuity of work. An RB.19 mounted over each portal handled the detachable skips unloading these into railway wagons standing in the approaches or on adjacent sidings from where they were regularly removed to tip.

116. The $2 \mathrm{ft}$ thick concrete invert had been cast in short bay lengths between the temporary steel struts at $10 \mathrm{ft} 6 \mathrm{in}$. centres over the entire tunnel length of $400 \mathrm{yds}$ using compressed air concrete pumps fed from a batching plant at each portal. In a total of $2300 \mathrm{cu}$. yds of concrete- $3000 \mathrm{lb} / \mathrm{sq}$. in. at twenty-eight days pumped into the new invert some difficulty had been experienced using ' 417 ' rapid hardening cement specified, but changing to 'Ferrocrete' gave improvement. As working space had been so restricted, the placing of the pumps up over the portals affected the pumping and contributed to a certain amount of segregation which took place. That was remedied at the delivery end by remixing during placing. After each bay had matured sufficiently, the temporary struts had been removed and re-used elsewhere and the inverts completed.

117. The invert had been designed to resist a partial upthrust and the ends had been toothed into the existing brickwork. The breaking out of this brickwork had proved excessively hard and the work could not keep pace with the J.C.B. machines carrying out the main excavation which resulted in considerable double-handling of the brick rubble.

118. Near the centre of the tunnel an existing $10 \mathrm{ft}$-dia. brick culvert under the wall footings had provided an outlet to the drainage system of the tunnel and its approaches. New drainage using 'Armco' pipes had been provided in the approaches both of which had been regraded for a distance of $300 \mathrm{yds}$, a 9 in. depth of sand blanketting also being laid.

119. Complete occupation of the Manchester Tunnel (No. 82A) and the approaches enabled the contractor, Sir Lindsay Parkinson \& Co. Ltd, by working two 12-h shifts for seven days a week with a peak labour force of 130 men on day and seventy on night shift, to fulfil the whole of the contract in the nine weeks' possession available.

120. In conclusion, he said, some credit for this achievement must go to all the railway departments concerned for their full co-operation during the contract.

Mr T. N. W. Akroyd (Consulting Engineer) said that he had been urged to speak by remarks made by Mr Sharman. While he did not feel called upon to defend $\mathrm{Mr}$ Burton, who was quite capable of doing that for himself, he did feel that there was a fundamental conflict between Mr Burton and Mr Sharman. Mr Burton was trying to do a difficult job; he was trying to carry out soil engineering. This was not the science of soil mechanics or soil testing. There was a world of difference between soil engineering and soil testing in which one could control precisely the conditions in the laboratory. This had been brought out clearly not long ago by Peck $^{5}$ in an article in Géotechnique in which this distinguished American author had drawn a distinction between the science of soil mechanics and the art of sub-surface engineering, or, as Mr Akroyd preferred to call it, soil engineering.

122. Mr Sharman had questioned the swelling tests. Perhaps the Authors would be a little more precise in saying how they had obtained the results. These were quite important, but they had not described sufficiently clearly what they had done. This left a certain amount of room for criticism.

123. Mr Akroyd said he did not necessarily agree with all Mr Burton's explanations, but he could not immediately suggest a radically different approach which would produce a nice, bright answer. The suggestion that because there was a failure, one started with a factor of safety of 1.0 and worked back from that was not necessarily the correct approach. If tests carried out on other jobs suggested that in this case the horizontal pressure would be equal to the overburden pressure, and when one adopted this it did not give a factor of safety of $1 \cdot 0$, then one could not 
scrap the previous tests as being inconvenient. To do so, made nonsense of soi] mechanics as a science.

124. But soil engineering was an art and was different. One assumed a fair engineering approach to the subject, and if that gave a factor of safety different from $1 \cdot 0$, this might not mean one had interpreted the results incorrectly; it might mean that one had not taken all the relevant factors into account.

125. The soil engineer did not know all the answers to a problem. One could not always carry out tests which reflected, with certainty, all the properties of a soil. If one carried out a test which lasted a week, or in some research projects lasted for several weeks, that was considered a long-term test. In fact, it was a short-term test simply because it did not take into account all the factors involved. Such tests took no account of slow creep, for example, and little was known about creep in these circumstances, and yet in long-term problems it was important. ${ }^{6}$ It was only when Professor Skempton ${ }^{7}$ had made investigations into the 'long term ' properties of overconsolidated clays, that an approach had been made to the problem. In soil engineering one seldom knew all the answers, but one was attempting to find an engineering solution to an engineering problem.

The Authors, in reply, thanked the contributors to the discussion for the comments which had been evoked, and which added much to the value of the Paper.

127. Mr Sharman's comment in $\S 72$ on the quoted clay swelling pressures might possibly be relevant to that part of the tunnel where the old brick invert had buckled and the footings had moved. Here the clay would have been disturbed (though hardly 'remoulded') and measured swelling pressures might be said for that reason, to be non-typical. But similar swelling pressures had been measured elsewhere in what was undoubtedly undisturbed clay under the tracks. It was clear that the clay could take up further water in very wet conditions, and was capable of swelling further and hence of losing strength despite the track overburden; and this had not been reassuring.

128. Swelling pressures were measured in an oedometer, the clay being kept saturated at constant volume and the piston being loaded as necessary to maintain this condition.

129. Referring to $\S 73$, the description given in $\$ 16$ of the envisaged failure mechanism might have been obscured by the necessity for condensation of the text. The heavy swelling pressures noted during the time of tunnel construction, were thought to have been caused in the end by the buckling of the old brick invert; the failure of this would indeed, as Mr Sharman said, have permitted the partial release of these pressures, which in consequence would fall to residual values with time (and probably were still falling until the new invert was built). But the swelling pressure had been resisted by the weight of overburden; as soon as the footings began to move inwards, although the swelling pressure fell, the clay behind the walls would tend to deform plastically, a re-distribution of stress would take place within it, and this would maintain pressure on the back of the footings. The magnitude of this pressure, whether due to swelling (where the brickwork was undisturbed) or due to plastic deformation (where the footings had moved) or due to a combination of the two could be regarded as a function of the overburden depth or of the residual strength of the footings.

130. Referring to $\S 74$, and to Fig. 7 , the thrust line illustrated had been drawn in conformity with what they believed was the generally accepted assumption that, for a plastic overconsolidated clay, the finally developed lateral/vertical $(L / V)$ ratio equalled $1 \cdot 0 .^{2}$ Mr Sharman had quoted assumptions made in Woodhead Tunnel design calculations; but there, it was submitted, he had been dealing with rock having elastic properties, and not with clay which tended to be plastic under sustained stress conditions. It would have been simple but unrealistic, to have drawn a thrust line to fall within the middle third of the lining section, and to have evolved an $L / V$ ratio 
to fit this solution. Nevertheless, although Fig. 7 represented what they thought was the worst case for design purposes, it was possible that lower $L / V$ ratios occurred elsewhere in the tunnel, particularly in the London half, where they could account for the observed comparative lack of lining distortion. Whether these conditions would continue to obtain in the future, was a matter about which they had been cautious.

131. The factors of safety had been criticized by Mr Sharman as being unrealistic. Those against inward movement could have been raised well above unity, by allowing for full frictional resistance at the brick-footing/clay interface-even between $29 \frac{1}{2}-30 \frac{1}{2}$ chains where failure had occurred. Probably this friction had some unknown and varying value; the quoted figures had nevertheless been thought useful, for comparison purposes.

132. Referring to $\S 76$ it was agreed that failure of the footings by downward movement would involve upward movement of the clay on one side only, but the factor of 5.5 times the cohesion was supported by Terzaghi. ${ }^{9}$ In $\S 20(e)$ the full horizontal thrust as shown in Fig. 7 had been considered in calculating the final safetyfactor provided.

133. In $\S 20(f)$ it was thought that the safety-factor of 2.0 was not excessively high when it was remembered that the possibility of creep of the clay had to be allowed for. Mr Toms had made a point that could not be too strongly stressed in railway tunnel repair work - it was essential to be safe rather than sorry.

134. Mr Toms had rightly called attention in $\S 85$ to the importance of regularly checking tunnel profiles and this was particularly important where the tunnel had been cut through clay. If checking could not be carried out at regular intervals, it was essential to have reliable initial records of the profiles taken at frequent spacings to enable the extent of any suspected future movement to be determined.

135. As Mr Reed had remarked in $\S 92$, the work could have been carried out much more quickly if it had not been necessary to carry traffic through the tunnel, but the train service had to be maintained with the need for adequately and safely supporting the track at all times. Very stringent precautions were also taken to ensure the safety of the personnel by means of safety barriers, special notice boards and an adequate warning system which enabled work to continue, even when the tunnel was filled with smoke with visibility only a few yards. It was a gratifying thought that no serious injuries were recorded throughout the whole work.

136. With regard to $\S 95$, it was, of course, true that the old rail reinforcement was cheap and to hand, and this fact had prompted its use. To incorporate (say) 2 in. dia. M.S. reinforcing with welded joints would have been extremely expensive. The fished joint in the centre of the old rails (Fig. 11) had the overwhelming practical advantage of being quick to complete. It would have been difficult to make a satisfactory and reliable welded joint and to do so would have entailed having welding plant and welders standing by throughout each shift just for this purpose, to say nothing of the access problems Mr Reed had mentioned.

137. Referring to $\S 94$, as stated earlier in $\S 130$ in reply to Mr Sharman, only an alteration in the $L / V$ pressure ratio on the tunnel lining would alter the position of the thrust line. Regarding §97, the apron slabs had been designed to span between the stretchers and had been keyed into them to avoid the trouble mentioned by $\mathrm{Mr}$ Reed.

138. In answer to Mr Shewring, much thought had been given to the most satisfactory way of carrying out the work and, apart from the economical aspect, the safety of traffic and personnel already mentioned in $\S 135$ was a predominant feature. A working length of $120 \mathrm{ft}(\S 32)$ was finally chosen to fulfil these conditions; furthermore, it would have been extremely difficult to have dealt with the water flowing through the 6-ft drain and percolating through the tunnel walls, if the work had been spread out over a greater length. Difficulties would also have arisen regarding the disposal of the spoil and handling of the materials and concrete in view of the limited space inside the tunnel. 
139. This $120 \mathrm{ft}$ working length therefore governed the number of men that could be economically employed on the work. By direct comparison it would appear that the total number of man-shifts worked at Gillingham Tunnel was just under three times the total number of man-shifts worked on the Manchester Tunnel. As Gillingham Tunnel is nearly twice as long as the Manchester Tunnel and the excavations and invert depths twice as deep, it would seem that the method of working at Gillingham was economically justified.

140. On an average it took $2 \frac{1}{2}$ shifts to simultaneously complete two $6 \mathrm{ft}$ wide half sections of invert, but much depended on the hardness of the formation being excavated. The $120 \mathrm{ft}$ long bays took about six weeks to complete, including the laying of the drain, ballasting, etc. The work proceeded from the Country end towards the London end.

141. With regard to the plant, the 19 R. B. crane was removed for use elsewhere during the three months' cessation of work but for the remaining plant the opportunity was taken to carry out complete and thorough overhauls.

142. The all-in crushed stone aggregate was specially graded by the supplier and was uscd to avoid the necessity of having two stock piles particularly as this material was unloaded in quantities of $200 \mathrm{cu}$. yd at a time. Furthermore, the use of weighbatchers was dispensed with as the mixer skips were suitably marked and also the mixers could travel along the stock pile, thus avoiding double handling. A very careful check was kept on the grading of the aggregate supplied and a seven day cube strength of $3000 \mathrm{lb} / \mathrm{sq}$. in. was regularly obtained. Apart from the bottom two footing courses, the brickwork was generally in excellent condition and very hard to break out.

143. So far as design matters were concerned, as Dr Ward had said in $\S 87$, it was easy to criticize the design of an old tunnel, but it was a fact that many were still performing admirably; and any theory as to the way in which they provided support to their surrounding soils had to account for a number of stubborn but anomalous facts, and a few of these might be suggested. For instance, why was an 'incorrectly' designed tunnel section capable in the main of continuing to give good service? As Mr Cantrell had said, it was a tribute to excellent past workmanship. The brickwork had been probed to determine its soundness at a number of places. At one point, where it was quite sound and undistorted, the clay $9 \mathrm{ft}$ behind the intrados had been found to have a shear strength of about $5000-6000 \mathrm{lb} / \mathrm{sq}$. ft. At another point where horizontal cracks were seen, the clay was found to be too hard to sample. Again, as in $\$ 11$, why was the clay under the tracks in the Country half of the tunnel slightly but appreciably stronger where it had failed first, than elsewhere?

144. The Authors had been aware of these anomalies, and they were grateful to $\mathrm{Mr}$ Akroyd for so concisely putting the problems of soil engineering in what they felt was their right perspective. Prof. Peck's comments had been quoted, and these were excellent, and could be regarded as going to the heart of the matter.

\section{REFERENCES}

4. P. A. Scott and J. I. CAmprell. Woodhead New Tunnel: construction of a three-mile main double-line railway tunnel. Proc. Instn civ. Engrs, vol. 3, 1954. pp. 506-578.

5. R. B. Peck. Art and science in sub-surface engineering. Géotechnique, vol. 12, January 1962, pp. 60-66.

6. K. Terzaght. Mechanism of landslides. 'Application of geology to engineering practice' (Berkey volume), 1950. Geological Society of America.

7. A. W. Skempton. The rate of softening in stiff-fissured clays, with special reference to London clay. Proc. 2 I.C.S.M. \& F.E. 2:50, 1948. 
8. H. D. Morgan. A contribution to the analysis of stress in a circular tunnel. Géotechnique, vol. 11, March 1961, pp. 37-46.

9. K. Terzaghr. 'Theoretical soil mechanics.' Chapman and Hall, London, 1944, p. 129.

\section{CORRIGENDA}

In the original Paper,

Page $65, \$ 6$, '60 invert-bay excavations' should read ' $30 \ldots$.

'Fig. 15' should read 'Fig. 16'.

$\S 8$, 'Fig. 16' should read 'Fig. 15'.

Page $69, \S 12, ' 77$ tests at average $\mathrm{M} / \mathrm{C} 18 \cdot 1$ ' should read ' 46 tests at average $\mathrm{M} / \mathrm{C} 16.9$ '. 